\title{
Cost evaluation of out-of-country care for patients with eating disorders in Ontario: a population-based study
}

\author{
Claire de Oliveira MA PhD, Erin M. Macdonald MSc, Diane Green BSc, Patricia Colton MD MSc, \\ Marion Olmsted PhD, Susan Bondy PhD, Paul Kurdyak MD PhD
}

\section{Abstract}

Background: Eating disorders, specifically anorexia nervosa, bulimia nervosa and eating disorder not otherwise specified, represent a substantial burden to the health care system. Our goal was to estimate the economic burden of patients who received specialized inpatient care for an eating disorder out of country.

Method: We conducted a cost-of-illness study evaluating health care costs among patients in Ontario who received specialized inpatient care for an eating disorder out of country from 2003 to 2011, from the public third-party payer perspective. Using linked administrative databases, we estimated net costs of eating disorders for 2 patient groups: those who received specialized inpatient care both out of country and in province $(n=160)$, and those who received specialized inpatient care out of country only $(n=126)$.

Results: Patients approved for specialized out-of-country inpatient care were mostly girls and young women from high-income, urban neighbourhoods. Total net costs varied annually and were higher for patients treated both out of country and in province (about $\$ 11$ million before 2007, $\$ 6.5$ million after) than for those treated out of country alone (about $\$ 5$ million and $\$ 2$ million, respectively). The main cost drivers were out-of-country care and physician services.

Interpretation: Costs associated with eating disorder care represent a substantial economic burden to the Ontario health care system. Given the high costs of out-of-country care, there may be opportunity to redirect these funds to increase capacity and expertise for eating disorder treatment within Ontario.

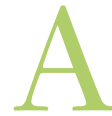

bout $3 \%$ of women are affected by an eating disorder in their lifetime. ${ }^{1}$ These disorders are associated with high levels of comorbid psychopathology, such as mood and anxiety disorders, posttraumatic stress disorder and substance use disorders. ${ }^{2}$ In addition, anorexia nervosa has the highest mortality rate of any psychiatric disorder. ${ }^{3}$ These consequences are reflected in high costs of care. ${ }^{2}$ Prior research suggests that age-adjusted treatment costs for anorexia nervosa and bulimia nervosa are comparable to those for schizophrenia. ${ }^{4}$ Other work has shown that eating disorders are associated with high direct and indirect health care costs. ${ }^{5}$ Yet, precise cost estimates are currently lacking.

Eating disorders represent a substantial economic burden to the Ontario health care system. To address this burden, the Ontario government made an investment in eating disorder treatment within the province in 2007. In addition, the Ontario Ministry of Health and Long-Term Care spends funds to send patients to the United States to receive specialized eating disorder treatment for complex cases, which cannot be treated inprovince owing to lack of resources, or when wait times for inprovince treatment are deemed unacceptably long. This care is specifically for patients with serious posttraumatic stress disor- der or substance use disorders concurrent with an eating disorder that interfere with treatment. Furthermore, some patients may receive additional specialized care in province; this is typically based on the care protocol defined by the specialist.

To be eligible for out-of-country care, patients must have an eating disorder diagnosed by a specialist at one of Ontario's funded inpatient programs for eating disorders. The specialist submits the application on behalf of the patient to the Ontario Out-of-Country Program, which makes decisions regarding coverage for medical and hospital services provided outside of Canada. This program reviews the application, undertaking research and/or consultations with experts as required, and decides whether coverage for the applicant is approved; the decision is based largely on disease severity.

\section{Competing interests: None declared.}

This article has been peer reviewed.

Correspondence to: Claire de Oliveira, claire.deoliveira@camh.ca CMAJ Open 2016. DOI:10.9778/cmajo.20160057 
It may be possible to divert funds spent on eating disorder care out of country to develop and augment programs within Ontario. This could potentially reduce overall costs, including out-of-pocket expenses, improve patients' experiences and create jobs in the province. ${ }^{6}$ Currently, there is no protocol for transitional or follow-up care on the patient's return to Ontario. Instead, follow-up care is provided by the patient's current care provider. Given the high risk of relapse during this transition period, disjointed care in different jurisdictions may contribute to poorer patient outcomes and additional treatment costs, although these data have not been collected.

The purpose of this study was to estimate the total costs of care for patients with an eating disorder who received out-ofcountry specialized care, from the perspective of the public third-party payer. A careful evaluation of these costs may be useful to determine whether developing further specialized services in province is financially justified.

\section{Methods}

\section{Study design and setting}

We conducted a cost-of-illness study. Our patient cohort included all those with an eating disorder covered under the Ontario Health Insurance Plan who applied for and received out-of-country specialized inpatient care from Apr. 1, 2000 to Mar. 31, 2012. We matched each patient to a set of control subjects with no history of an eating disorder to estimate net costs.

During our analysis period, the Ontario government in 2007 made a significant investment in eating disorder treatment within the province. This led to a decrease in the number of out-of-country applications.

\section{Data sources}

We obtained data for all patients who received out-of-country care for eating disorders from the Ministry of Health and Long-Term Care's Out-of-Country Program database, which includes all records on out-of-country care. These data included information on the status of the application (approved, denied, cancelled, awaiting information, pending), name of the out-of-country provider, total amount billed and paid by the province, service start and end dates, and condition for which care was provided (eating disorder, substance abuse, other psychiatric disorder). Further information on the Out-of-Country Program can be found elsewhere. ${ }^{?}$

In addition, we used administrative health care databases available through the Institute for Clinical Evaluative Sciences, Toronto, to obtain data on all health care services provided within the province and covered by the Ministry of Health and Long-Term Care only. These databases have been validated and described in the literature ${ }^{8}$ and have been used previously for costing analyses in Ontario. ${ }^{9-11}$ A full description of each database can be found in Appendix 1 (available at www.cmajopen.ca/content/4/4/E661/suppl/ DC1). The databases were linked with the use of unique encoded identifiers and analyzed at the Institute for Clinical Evaluative Sciences.

\section{Patient cohort}

We included patients with a diagnosis of anorexia nervosa, bulimia nervosa or eating disorder not otherwise specified (International Classification of Diseases [ICD], 9th revision codes 307.1, 307.5 and 307.51; ICD-10 codes F50.0-F50.3, F50.8 and F50.9; and Diagnostic and Statistical Manual of Mental Disorders, 4th edition codes 307.1, 307.50 and 307.51). We excluded patients with Prader-Willi syndrome (ICD-9 code 759.81; no specific ICD-10 code was available), a rare genetic disorder associated with excessive eating and obesity; patients who did not reside in Ontario at the time of diagnosis; patients who did not have a valid Ontario Health Insurance Plan number during the analysis period; and patients with missing information on age or sex. We also excluded patients who first applied for out-of-country care outside the study period, patients who were denied out-of-country care or whose out-of-country care was cancelled, and patients with missing information on the out-of-country care application status. Our final cohort included all patients who received specialized eating disorder treatment out of country (and thus had similar disease severity). The cohort was divided into 2 groups according to whether or not patients received specialized inpatient care in province in addition to out of country.

\section{Analysis}

\section{Sociodemographic and clinical characteristics}

We compared the 2 patient groups on sociodemographic characteristics, such as age, sex, neighbourhood income quintile (at the census tract level) and urban/rural residence, and comorbidity, such as diabetes, asthma and hypertension, which were defined with the use of validated algorithms. ${ }^{12-14}$

\section{Estimation of costs of care}

Costs for out-of-country care were available in the Ontario Health Insurance Plan claims database (fee codes H700, H820, H830 and H850). We converted costs, in US dollars, to Canadian dollars using monthly exchange rates and adjusted them to 2012 values.

To estimate direct costs for in-province care, we used a costing algorithm ${ }^{8}$ available at the Institute for Clinical Evaluative Sciences. Because complete cost data were not available for the entire analysis period, we estimated them for 2003 to 2011 only. Costs included costs of inpatient hospital stays (psychiatric and nonpsychiatric), emergency department visits, other ambulatory care, physician visits, laboratory tests, outpatient prescription drugs covered under the public provincial drug program, complex continuing care, long-term care, home care, rehabilitation and assistive devices (Appendix 1).

The standard costing methodology used a bottom-up (microcosting) approach to cost services at the individual level. ${ }^{8}$ This approach considered individual episodes of care or use of services in the health care system and attached prices (or costs or amounts paid by the Ministry of Health and Long-Term Care) to each one. When individual unit costs were not available (for example, for institutional care settings), the algorithm applied a top-down approach, which allocates 
corporate aggregate (institutional) costs to individual visits or to cases or episodes of care. ${ }^{8}$ Further details on the costing methodology can be found elsewhere. ${ }^{8}$

Many cost-of-illness studies have been criticized for attributing all costs to a single disorder, when most patients have other health problems that also require care. ${ }^{15}$ Therefore, we used the "net cost" method to obtain an estimate of the cost of treating an eating disorder. This method consists of matching patients who have an eating disorder to patients who do not have an eating disorder (control subjects) on variables associated with resource use and subtracting the costs incurred by the former from those incurred by the latter. ${ }^{16-18}$ We matched patients with an eating disorder to control subjects on age, sex and neighbourhood income quintile on a 1:4 ratio. We applied the net cost method only to costs incurred in Ontario; out-ofcountry costs were over and above net costs.

\section{Ethics approval}

This study was approved by the Research Ethics Board at Sunnybrook Health Sciences Centre, Toronto.

\section{Results}

During the study period, there were 1854 applications for out-of-country care. We excluded applicants who did not meet our definition of eating disorder care $(n=1295)$, those who first applied outside our study window $(n=62)$ and those who were denied out-of-country care, whose care was cancelled or who had missing information $(n=211)$ (Figure 1). Patients who were approved care were younger than those denied care (median age 18 v. 23, respectively) but were similar on all other patient characteristics (data not shown). This was also the case for those whose care was cancelled and those with missing information. Our final cohort included all patients who first applied and were approved for out-of-country care between fiscal years 2000/01 and 2012/13 $(n=286)$. Of the 286,160 also received specialized inpatient care in province during the study period, and 126 did not. There were 1144 control subjects.

\section{Sociodemographic and clinical characteristics}

The patients who also received specialized inpatient care in province during the study period and those who did not differed in age (mean 20.3 [standard deviation 7.6] yr v. 24.2 [standard deviation 10.3] yr, $p<0.001$ ) and sex (significantly more patients who received specialized care out of country only were male, $p=0.03$ ) but were similar on all other sociodemographic and clinical characteristics (Table 1). Most patients were from high-income, urban neighbourhoods. Less than $7 \%$ of patients had diabetes or hypertension; about one-quarter had asthma.

\section{Estimation of costs}

The number of funded applications for out-of-country specialized inpatient care increased from 2000 to 2006 and decreased thereafter (Figure 2). Total annual net costs varied with the number of applications approved each year. Overall, there was an inverted $U$-shaped curve in costs over time for both patient groups (Figure 3, A and B).

Total annual costs were about \$5 million before 2007 and $\$ 2$ million thereafter for patients who received specialized inpatient care out of country only (Figure 3, A), and $\$ 11$ million and $\$ 6.5$ million, respectively, for patients who received specialized inpatient care both out of country and in province (Figure 3, B).

In-province costs for patients who received specialized inpatient care out of country only were just under $\$ 3$ million per year until 2007 and decreased to around \$1.5 million per year thereafter (Figure 3, A). Out-of-country costs for this group were slightly lower than in-province costs and followed a similar temporal pattern (\$2.3 million before 2007, \$0.5 million after) (Figure 3, A).

In-province costs were substantially higher for patients who received specialized care both out of country and in province — just under \$7 million annually until 2007 (except in 2003) and about $\$ 5$ million per year afterward ${ }^{3}$ (Figure 3, B). Out-ofcountry costs were slightly lower but followed a similar pattern (around $\$ 4$ million in the first years and about $\$ 1.5$ million in the later years) (Figure 3, B).

On average, out-of-country inpatient care and physician costs were the largest contributors to the overall cost for both

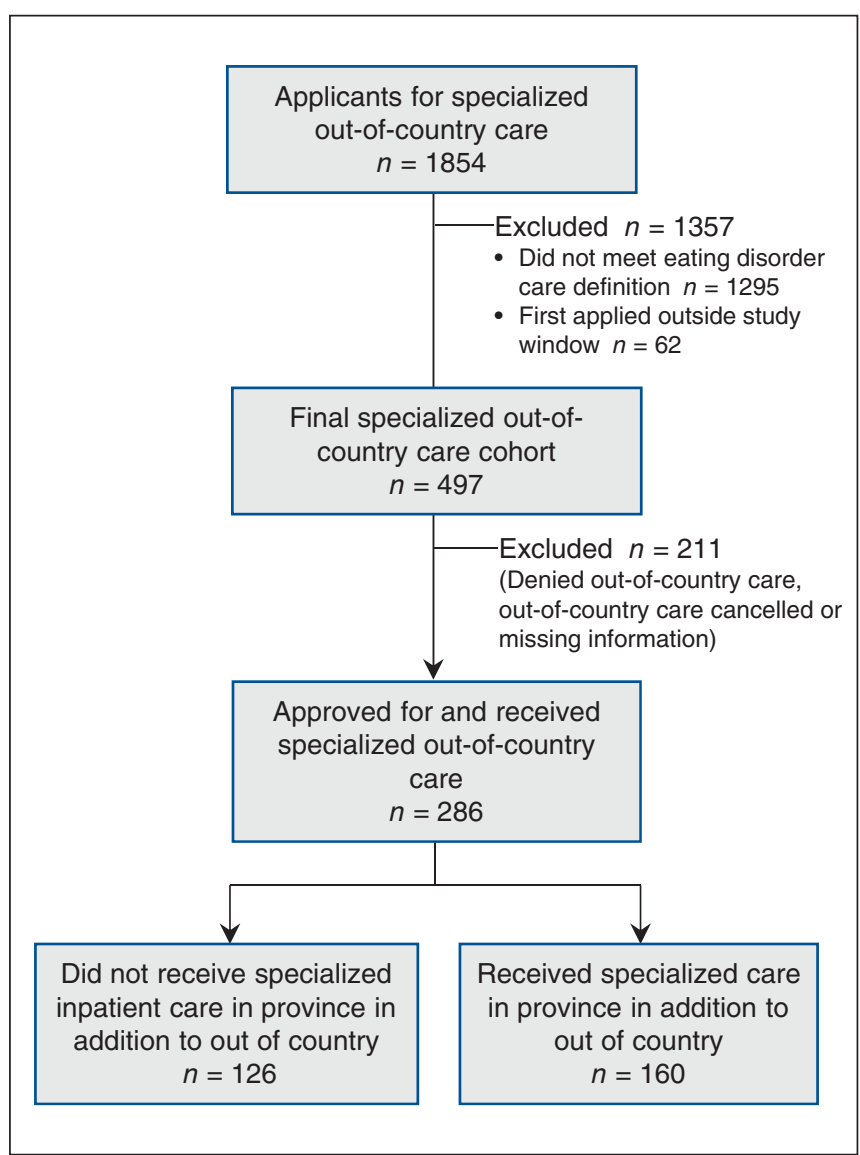

Figure 1: Patient selection flow chart for Ontario patients with eating disorders who applied for specialized out-of-country care from Apr. 1, 2000 to Mar. 31, 2012. 


\begin{tabular}{|c|c|c|c|}
\hline \multirow[b]{2}{*}{ Characteristic } & \multicolumn{2}{|c|}{ No. $(\%)$ of patients* } & \multirow[b]{2}{*}{$p$ value } \\
\hline & $\begin{array}{l}\text { Received specialized } \\
\text { inpatient care out of } \\
\text { country only } \\
(n=126)\end{array}$ & $\begin{array}{l}\text { Received specialized } \\
\text { inpatient care both out } \\
\text { of country and in } \\
\text { province } \\
(n=160)\end{array}$ & \\
\hline \multicolumn{4}{|l|}{ Sex } \\
\hline Male & $11(8.7)$ & $\leq 5$ & 0.03 \\
\hline Female & $115(91.3)$ & $\leq 155$ & \\
\hline \multicolumn{4}{|l|}{$\begin{array}{l}\text { Age at time of first } \\
\text { application, } y r\end{array}$} \\
\hline Mean \pm SD & $24.2 \pm 10.3$ & $20.3 \pm 7.6$ & $<0.001$ \\
\hline Median (IQR) & $21(17-28)$ & $17(16-23)$ & \\
\hline \multicolumn{4}{|c|}{$\begin{array}{l}\text { Neighbourhood income } \\
\text { quintile }\end{array}$} \\
\hline 1 (lowest) & $16(12.7)$ & $19(11.9)$ & 1.0 \\
\hline 2 & $14(11.1)$ & $19(11.9)$ & \\
\hline 3 & $25(19.8)$ & $30(18.8)$ & \\
\hline 4 & $26(20.6)$ & $32(20.0)$ & \\
\hline 5 (highest) & $45(35.7)$ & $60(37.5)$ & \\
\hline Rural residence & $13(10.3)$ & $11(6.9)$ & 0.3 \\
\hline \multicolumn{4}{|c|}{ Comorbid condition } \\
\hline Diabetes & $6(4.8)$ & $\leq 5$ & 0.3 \\
\hline Asthma & $30(23.8)$ & $39(24.4)$ & 0.9 \\
\hline Hypertension & $7(5.6)$ & $11(6.9)$ & 0.3 \\
\hline
\end{tabular}

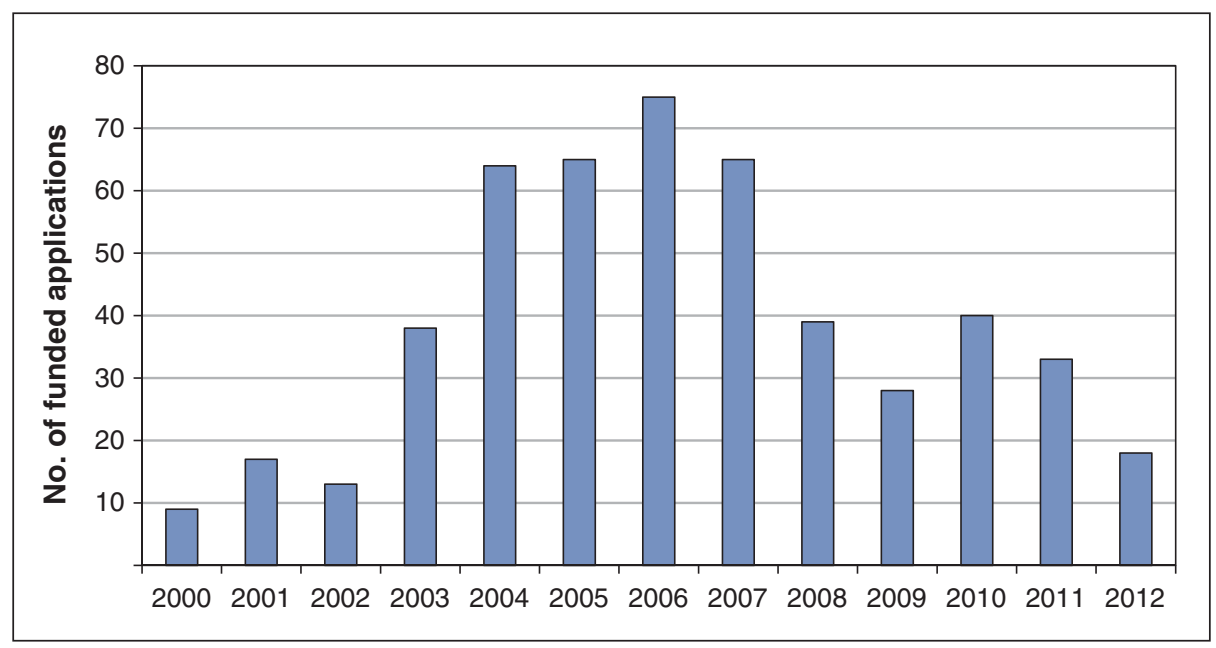

Figure 2: Number of funded applications for specialized out-of-country care for an eating disorder by year of application. Note: 2012 does not correspond to the full fiscal year as full data were not available at the time of the analysis. 
patient groups. Costs of inpatient hospital stays were also important cost drivers, mainly for patients who also received specialized care in province. Costs of other health care services represented a small proportion $(\leq 5 \%)$ of the overall cost for all patients (data not shown).

\section{Interpretation}

We estimated total net costs for patients who received specialized inpatient care for eating disorders out of country. Most patients were young, female and from high-income, urban neighbourhoods. Total net costs were higher for patients who received specialized inpatient care both out of country and in province, which suggests that these patients represent complex cases. The major contributors to the overall cost were out-of-country care, physician services and, to a lesser degree, in-province inpatient hospital stays. Although we observed a decrease in costs after 2007, when there were significant changes in the Ontario Out-of-Country Program, ${ }^{19}$ the costs of this program remained a relatively large component of the economic burden of eating disorders to the province.

A comprehensive literature review identified only 6 studies worldwide on health services use and costs among patients with an eating disorder. Most studies were dated, and results varied greatly. ${ }^{5}$ In the United Kingdom, the direct cost to the health care system of anorexia nervosa was estimated at $£ 4.2$ million in $1990 .^{20}$ In Germany, costs in 1998 were $€ 65$ million for anorexia nervosa and $€ 10$ million for bulimia nervosa. ${ }^{21}$ In Australia, health care costs of eating disorders were A\$22 million in 1993/94. ${ }^{22}$ Other cost studies that focused mostly on inpatient care gave highly variable estimates. More recent work from the UK showed that total treatment costs to the National Health Service may vary between $£ 3.9$ billion and $£ 4.6$ billion. ${ }^{23}$ Despite high use of

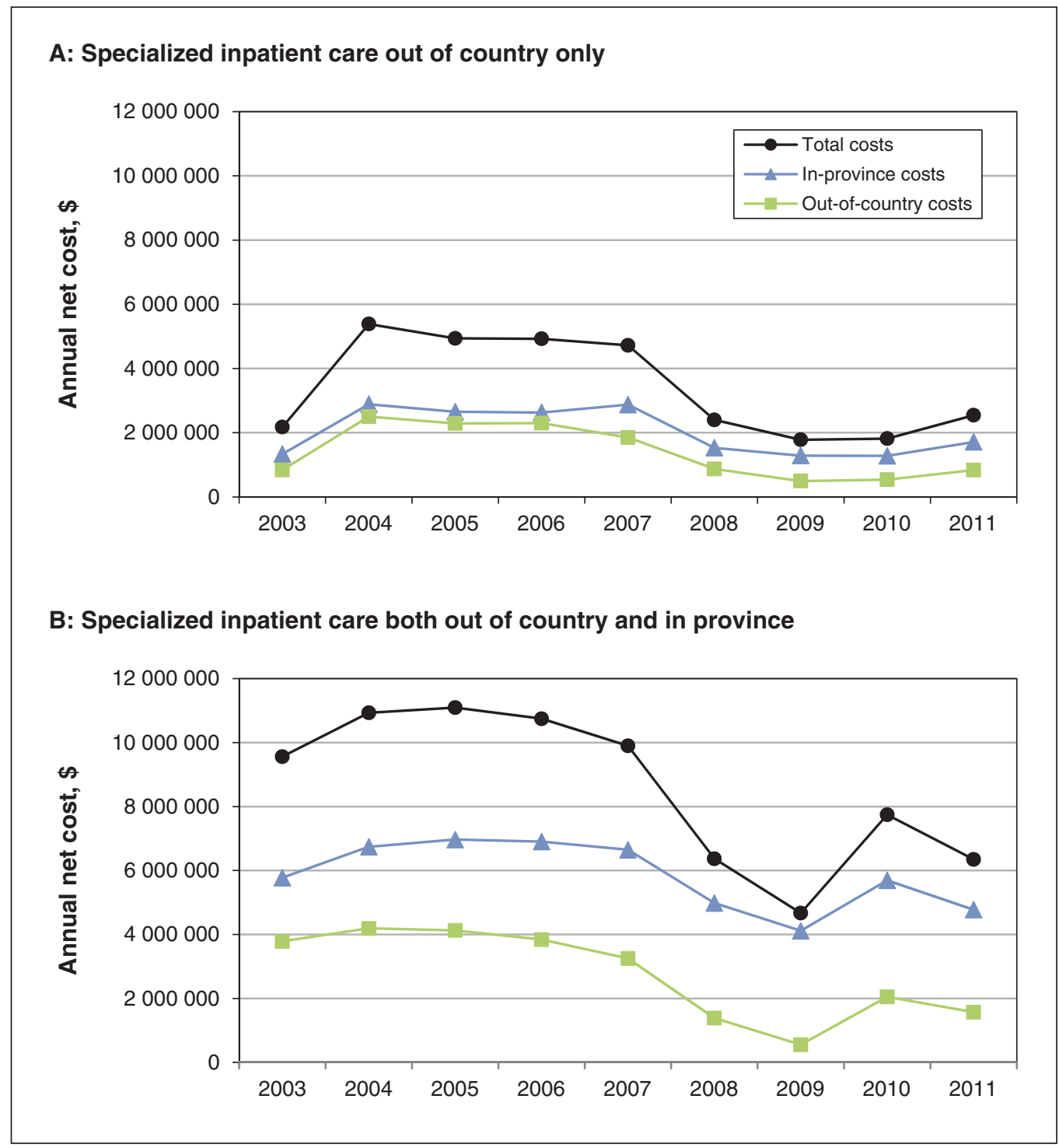

Figure 3: Total annual net costs for patients with eating disorders who received specialized inpatient care out of country only (A) or both out of country and in province (B), 2003 to 2011 . All costs are in 2012 Canadian 
health care services among patients with an eating disorder, results in most studies are likely gross underestimates of the full magnitude of the economic burden, as only inpatient costs were captured ${ }^{21}$ or results were based on limited cost data. ${ }^{4}$ Furthermore, in only 1 study $^{4}$ did the authors report specific information on the use of services by patients with "eating disorder not otherwise specified," the most common diagnosis encountered in clinical practice. ${ }^{24} \mathrm{We}$ did not find any studies that estimated net costs or that examined an out-of-country program; thus, our estimates are not directly comparable to previous work. Nonetheless, we found that our estimates were quite substantial even for a small group of patients with outof-country costs representing a small proportion of the Ontario health care budget (0.005\% in 2012). ${ }^{25}$ Evidence suggests that average daily treatment costs in province are lower than those out of country (\$918 v. $\$ 1285$, respectively). ${ }^{6}$

Complete cost estimates for patients with an eating disorder are required to determine cost-effective treatment options, ${ }^{5}$ yet these are generally lacking in the literature. ${ }^{26}$ Few investigators have examined the cost-effectiveness of eating-disorder-related interventions. ${ }^{27}$ Thus, our cost estimates may be useful inputs for researchers conducting economic evaluations. Furthermore, they may help inform policy discussions in Ontario and other jurisdictions with similar funded out-of-country care programs, such as British Columbia.

The ongoing need for out-of-country care for Ontario patients with an eating disorder likely reflects inability to access care and/or to adequately manage complexity within eating disorder cases. TOhere is a need for greater variability in and availability of comprehensive care for these patients across the province, ideally aligned with patients' needs — in other words, regionalized care with higher levels of coordination, perhaps like the Ontario cancer care system. An ideal model of care might provide availability of basic services across the province but have expertise for more complex cases centralized in large urban centres, as in the Netherlands. ${ }^{28}$ This alignment could potentially improve care transitions and follow-up care, which are crucial given the high rates of relapse among these patients. ${ }^{29,30}$

\section{Strengths and limitations}

Our study examined an important policy issue within the Ontario health care system and addressed a gap in the literature. Thus far, even internationally, there has been little research on the costs of treating eating disorders. ${ }^{4,31}$ Furthermore, whereas most previous studies examined only inpatient and outpatient costs for subgroups of patients, we estimated total net costs for a specific group of patients with an eating disorder. Unlike other studies, our cost estimates represents the direct cost of eating disorders themselves.

Our study was limited by that fact that we were not able to account for addiction-related health care costs incurred by community-based agencies, where a large part of addiction treatment is provided. ${ }^{32}$ In addition, we were not able to capture outpatient treatment for eating disorders funded by the Ontario Health Insurance Plan other than that provided directly by psychiatrists. We were able to include only costs of outpatient prescription drugs for patients covered by the public provincial drug program (for this cohort, people receiving social assistance). Thus, our cost estimates are likely an underestimate. We also had limited ability to examine subpopulations of interest (e.g., male v. female, type of eating disorder, psychiatric comorbidity) and included only patients who were approved for out-of-country care. Finally, we estimated direct costs incurred by the health care system and did not estimate other relevant costs, such as those covered under private health care plans, out-of-pocket costs, costs related to inability to work (lost productivity) for patients and family members, and costs associated with death, which are also lacking in the literature. Future research should seek to estimate these other relevant costs.

\section{Conclusion}

Costs of care associated with eating disorders are large and represent a substantial financial burden to the health care system. We found that patients who received specialized inpatient care both out of country and in Ontario had higher costs than those treated out of country alone. Furthermore, we found that the main cost drivers were out-of-country care and physician services. Given the high costs associated with outof-country care, there may be opportunity to redirect these funds to increase capacity and expertise for eating disorder treatment within Ontario; this could reduce overall costs of care, improve patients' experiences and create new jobs in the province. This would require additional analyses around the estimation of cost-savings to the system in the long run and the implications for patient outcomes.

\section{References}

1. Zhu AJ, Walsh BT. Pharmacologic treatment of eating disorders. Can 7 Psychiatry $2002 ; 47: 227-34$.

2. Agras WS. The consequences and costs of the eating disorders. Psychiatr Clin North Am 2001;24:371-9.

3. Sullivan PF. Mortality in anorexia nervosa. Am f Psychiatry 1995;152:1073-4.

4. Striegel-Moore RH, Leslie D, Petrill SA, et al. One-year use and cost of inpatient and outpatient services among female and male patients with an eating disorder: evidence from a national database of health insurance claims. Int 7 Eat Disord 2000;27:381-9.

5. Simon J, Schmidt U, Pilling S. The health service use and cost of eating disorders. Psychol Med 2005;35:1543-51.

6. Helping youth with eating disorders get care closer to home [news release]. Toronto: Ontario Ministry of Health and Long-Term Care; 2014. Available: https://news.ontario.ca/mohltc/en/2014/03/helping-youth-with-eating-disorders -get-care-closer-to-home.html (accessed 2016 June 29).

7. Ministry programs: Ontario Health Insurance Plan - OHIP Out of Country Health Services. Toronto: Ontario Ministry of Health and Long-Term Care; 2012. Available: www.health.gov.on.ca/en/public/programs/ohip/outofcountry/ default.aspx (accessed 2016 Apr. 20).

8. Wodchis W, Bushmeneva K, Nikitovic M, et al. Guidelines on person-level costing using administrative databases in Ontario. vol 1 of Working paper series. Toronto: Health System Performance Research Network; 2013.

9. de Oliveira C, Bremner KE, Pataky R, et al. Understanding the costs of cancer care before and after diagnosis for the 21 most common cancers in Ontario: a population-based descriptive study. CMA7 Open 2013;1:E1-8.

10. de Oliveira C, Bremner KE, Pataky R, et al. Trends in use and cost of initial cancer treatment in Ontario: a population-based descriptive study. CMAJ Open 2013;1:E151-8.

11. de Oliveira C, Cheng J, Vigod S, et al. Patients with high mental health costs incur over 30 percent more costs than other high-cost patients. Health Aff (Millwood) 2016;35:36-43.

12. Hux JE, Ivis F, Flintoft V, et al. Diabetes in Ontario: determination of prevalence and incidence using a validated administrative data algorithm. Diabetes Care 2002;25:512-6.

13. Gershon AS, Wang C, Guan J, et al. Identifying patients with physician diagnosed asthma in health administrative databases. Can Respir 7 2009;16:183-8. 
14. Tu K, Chen Z, Lipscombe LL; Canadian Hypertension Education Program Outcomes Research Taskforce. Prevalence and incidence of hypertension from 1995 to 2005: a population-based study. CMA7 2008;178:1429-35.

15. Knapp M, Mangalore R, Simon J. The global costs of schizophrenia. Schizophr Bull 2004:30:279-93.

16. Taplin SH, Barlow W, Urban N, et al. Stage, age, comorbidity, and direct costs of colon, prostate, and breast cancer care. 7 Natl Cancer Inst 1995;87:417-26.

17. Brown ML, Riley GF, Potosky AL, et al. Obtaining long-term disease specific costs of care: application to Medicare enrollees diagnosed with colorectal cancer. Med Care 1999;37:1249-59.

18. Yabroff KR, Lamont EB, Mariotto A, et al. Cost of care for elderly cancer patients in the United States. 7 Natl Cancer Inst 2008;100:630-41.

19. External review of the Ontario Health Insurance Plan's Out-of-Country Program. Toronto: Ministry of Health and Long-Term Care; 2007. Available: www.health.gov.on.ca/en/common/ministry/publications/reports/out_of_country_ ohip/out_of_country_ohip.aspx (accessed 2016 Oct. 28).

20. West R. Eating disorders: anorexia nervosa and bulimia nervosa. London (UK): Office of Health Economics; 1994.

21. Krauth C, Buser K, Vogel H. How high are the costs of eating disorders anorexia nervosa and bulimia nervosa - for German society? Eur 7 Health Econ 2002;3:244-50.

22. Mathers C, Vos T, Stevenson C. The burden of disease and injury in Australia. AIHW cat no PHE 17. Canberra (Australia): Australian Institute of Health and Welfare; 1999.

23. The costs of eating disorders - social, health and economic impacts. Norwich (UK): Beat; 2015. Available: https://www.b-eat.co.uk/assets/000/000/302/The_ costs_of_eating_disorders_Final_original.pdf (accessed 2016 June 28).

24. Fairburn CG, Bohn K. Eating disorder NOS (EDNOS): an example of the troublesome "not otherwise specified" (NOS) category in DSM-IV. Behav Res Ther 2005;43:691-701.

25. Ministry of Health and Long-Term Care - the estimates, 2012-13 - summary. Oshawa (ON): Ontario Ministry of Finance; 2012. Available: www.fin. gov.on.ca/en/budget/estimates/2012-13/volume1/MOHLTC.html (accessed 2016 June 29).

26. Hay PJ, Mond J. How to 'count the cost' and measure burden? A review of health-related quality of life in people with eating disorders. 7 Ment Health 2005;14:539-52.

27. Crow SJ, Nyman JA. The cost-effectiveness of treatment for anorexia nervosa. Int 7 Eat Disord 2004;35:155-60.

28. Cramm JM, Tsiachristas A, Adams SA, et al. Evaluating disease management programmes in the Netherlands. Rotterdam (the Netherlands): Institute of Health Policy \& Management, Erasmus University Rotterdam; 2014.

29. Olmsted MP, Kaplan AS, Rockert W. Rate and prediction of relapse in bulimia nervosa. Am 7 Psychiatry 1994;151:738-43.

30. Carter JC, Mercer-Lynn KB, Norwood SJ, et al. A prospective study of predictors of relapse in anorexia nervosa: implications for relapse prevention. Psychiatry Res 2012;200:518-23.
31. Toulany A, Wong M, Katzman DK, et al. Cost analysis of inpatient treatment of anorexia nervosa in adolescents: hospital and caregiver perspectives. $C M A \mathcal{A}$ Open 2015;3:E192-7.

32. Ogborne AC, Braun K, Rush BR. Developing an integrated information system for specialized addiction treatment agencies. 7 Behav Health Serv Res 1998; 25:100-7.

Affiliations: Centre for Addiction and Mental Health (de Oliveira, Kurdyak); Institute for Health Policy, Management and Evaluation (de Oliveira, Kurdyak), University of Toronto; Institute for Clinical Evaluative Sciences (de Oliveira, Macdonald, Green, Bondy, Kurdyak); Toronto General Hospital (Colton, Olmsted), University Health Network; Department of Psychiatry (Colton, Olmsted, Kurdyak), University of Toronto; Dalla Lana School of Public Health (Bondy), University of Toronto, Toronto, Ont.

Contributors: Claire de Oliveira contributed to the conceptualization and design of the study, analyzed and interpreted the data and drafted the manuscript. Patricia Colton and Marion Olmsted provided expert advice on the topic. Diane Green obtained the data and linked them with administrative health care data, and analyzed the data under the guidance of the first author. Erin Macdonald, Patricia Colton, Marion Olmsted, Susan Bondy and Paul Kurdyak contributed to the conceptualization and design of the study, analyzed and interpreted the data, and revised the manuscript critically for important intellectual content. All of the authors approved the final version to be published and agreed to act as guarantors of the work.

Disclaimer: This study was supported by the Institute for Clinical Evaluative Sciences (ICES) which is funded by an annual grant from the Ontario Ministry of Health and Long-Term Care (MOHLTC). The opinions, results and conclusions reported in this article are those of the authors and are independent from the funding sources. No endorsement by the ICES or the Ontario MOHLTC is intended or should be inferred. Parts of this material are based on data and information compiled and provided by the Canadian Institute for Health Information (CIHI). However, the analyses, conclusions, opinions and statements expressed herein are those of the authors and not necessarily those of the CIHI.

Supplemental information: For reviewer comments and the original submission of this manuscript, please see www.cmajopen.ca/content/4/4/ E661/suppl/DC1 